\title{
SANDZ000-2575C
}

\section{Mass Estimates of Very Small Reactor Cores Fueled by Uranium-235, U-233 and Cm-245}

\author{
Steven A. Wright , Ronald J. Lipinski \\ Sandia National Laboratories, MS-1146, PO Box 5800, Albuquerque NM, 87185 \\ Email: sawright@sandia.gov, rilipin@sandia.gov \\ Phone: (Wright) 505-845-3014), (Lipinski) 505-844-7311
}

\begin{abstract}
This paper explores the possibility of manufacturing very small reactors from U-235, U-233 and Cm245. Pin type reactor systems fueled with uranium or curium metal zirconium hydride ( $\mathrm{UrH}$ or $\mathrm{CmZrH}$ ) are compared with similar designs using U-235. Criticality measurements of homogeneous water uranium systems, suggest that reactor subsystem masses have a broad minimum for hydrogen-to-uranium atom ratios that vary from 25- 250. This paper compares the masses of metal-hydride fueled reactor systems that use U-235, U-233, and Cm-245 fuel with hydrogen-to-metal atom ratios from 20-300 when cooled by gas (HeXe), liquid metal $(\mathrm{Na})$, and water. The results indicate that water cooled reactors in general have the smallest reactor subsytem mass. For gas and liquid-metal cooled reactors U-233 subsystems have total masses that are about $1 / 2$ those of similarly designed U-235 fuel reactors. Reactor subsystems consisting of $11.2 \%$ enriched Cm-245 (balance $\mathrm{Cm}-244$ ) that can be obtained from fuel reprocessing have system masses comparable to that of U-233. The smallest reactor subsystem masses were on the order of $60-80 \mathrm{~kg}$ for U-233 fueled water cooled reactors.
\end{abstract}

\section{INTRODUCTION}

Very small compact reactors will have great utility as power supplies for ambitious space missions to the outer planets or as portable or transportable power sources on the surface of planets. This paper explores the possibility of using alternative fissionable isotopes such as U-233 and Cm-245 for small space reactors. For this paper, only pin type reactor systems fueled with uranium or curium metal zirconium hydride ( $\mathrm{UZrH}$ or $\mathrm{CmZrH}$ ) were considered. Other fuel forms and chemical compositions are of course possible including plate type fuels (or particle bed fuels) made from carbides, oxides or metal based dispersion fuels. For very small reactors that do not require high power, it is highly likely that these alternative geometry configurations could produce compact reactor designs as small or smaller than those presented here. Nevertheless, in the interest of time, this paper restricts itself to pin type reactors that use metal hydride dispersion fuel.

\section{SMALL IDEAL CRITICAL SYSTEMS}

The nuclear criticality safety community has collected a large amount of data in the effort to preclude inadvertent assembly of critical systems. This information most often describes the amount of U-235 or other fissile material that is required to form a critical mass in various geometries and moderator mixtures. This data has been used here to estimate the size and configuration of minimum mass reactor subsystems. Generally two types of critical systems are considered that represent the extremes of reactor fuels under consideration. One extreme is a critical system that is an optimally water moderated system (solution type 


\section{DISCLAIMER}

This report was prepared as an account of work sponsored by an agency of the United States Government. Neither the United States Government nor any agency thereof, nor any of their employees, make any warranty, express or implied, or assumes any legal liability or responsibility for the accuracy, completeness, or usefulness of any information, apparatus, product, or process disclosed, or represents that its use would not infringe privately owned rights. Reference herein to any specific commercial product, process, or service by trade name, trademark, manufacturer, or otherwise does not necessarily constitute or imply its endorsement, recommendation, or favoring by the United States. Government or any agency thereof. The views and opinions of authors expressed herein do not necessarily state or reflect those of the United States Government or any agency thereof. 


\section{DISCLAIMER}

Portions of this document may be illegible in electronic image products. Images are produced from the best available original document. 
reactor or dilute uranium lattice in water). Because this reactor has an effective neutron moderator (hydrogen) it will generally lead to systems having minimum mass of $\mathbf{U}-235$. The second extreme consists of a spherical metal reactor that is water reflected. This type reactor will generally have the minimum size. This information is conveniently represented as a curve of mass versus hydrogen to metal atom ratio in Figure 1 (Knief 1988). The critical mass of U-235 for a water-moderated reactor with a $25 \mathrm{~mm}$ reflector is shown as the red (solid) curve. For uranium concentrations less that about $0.3 \mathrm{~kg}$-U/liter this type of reactor is typically a solution reactor of $\mathrm{UO}_{2} \mathrm{~F}_{2}$ dissolved in water to the desired concentration. Note that only $780 \mathrm{~g}$ of U-235 are required to make the system critical for fully enriched uranium concentrations near $0.05 \mathrm{~kg} / \mathrm{liter}$. A reactor of this configuration would have a diameter of about $42-45 \mathrm{~cm}$. For uranium concentrations above $\sim 5 \mathrm{~kg} /$ liter the reactor is approaching a water reflected bare-metal system configuration. For intermediate uranium concentrations $(0.1-2 \mathrm{~kg} /$ liter $)$ above about $0.2 \mathrm{~kg}$-U/liter the reactor can be configured as an array of uranium fuel plates or pins moderated by water.

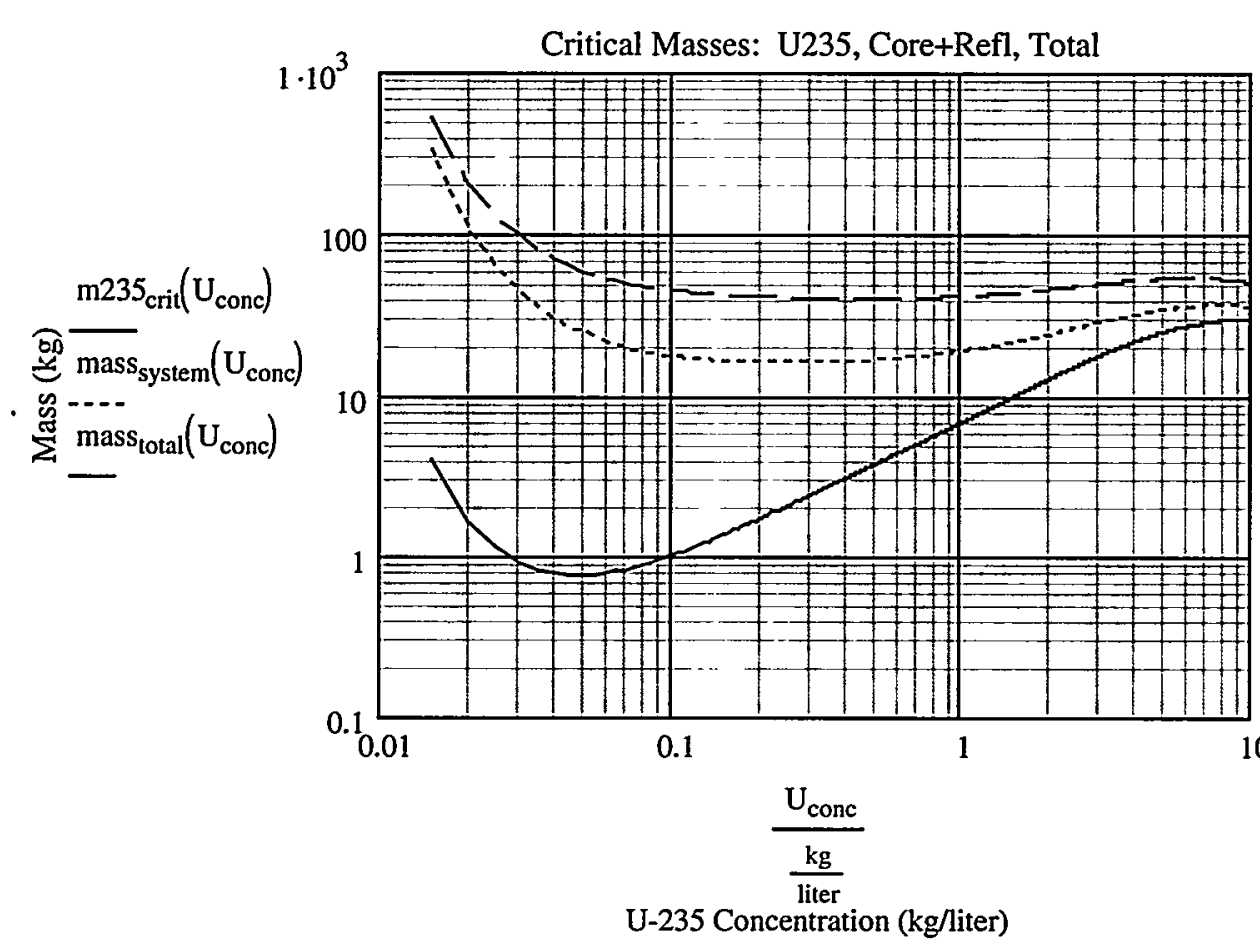

$\{+\sqrt{4}\{$,

NOV 152000

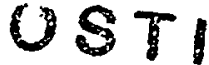

FIGURE 1. Critical mass and system masses for spheres of homogeneous water-moderated and water-reflected U-235 solutions. Red (solid) curve shows the critical mass. Blue (dotted) curve shows the estimates of the solution mass plus the $25 \mathrm{~mm}$ water reflector. Black (dashed) curve shows the total system mass including a $1 \mathrm{~cm}$ thick nickel alloy containment with average density of $8 \mathrm{~kg} /$ liter.

Estimates for the combined mass of the uranium plus water solution mass and the $25 \mathrm{~mm}$ water reflector are also shown in Figure 1 as the blue curve. The combined masses were estimated by assuming that the volume fraction of the uranium is small and that the water solution weighs $1 \mathrm{~kg} / \mathrm{liter}$. The total mass is shown in black (dashed) and assumes a $1 \mathrm{~cm}$ thick pressure vessel having a density of $8 \mathrm{~kg} /$ liter. Notice that the core + reflector + pressure vessel mass (black curve) has a broad minimum from 0.1 to $2.0 \mathrm{~kg} /$ liter. Systems of this configuration typically have a diameter of $30 \mathrm{~cm}$ and a core + reflector mass of $20 \mathrm{~kg}$.

It is assumed here that this figure generally represents the situation for a wide variety of reactor designs. If this is the case, then there are a number of observations that one should conclude:

1. Reactors subsystems are most likely to have the least mass if they use hydrogen as a moderator,

2. The total reactor subsystem mass minimum is broadly distributed over a range of hydrogen-to-fissile metal atom ratios and results in reactor subsystem masses of $40-50 \mathrm{~kg}$ for a water moderated solution reactor, and 
3. The reactor subsystem mass will be minimized at uranium concentrations of $0.2-2 \mathrm{~kg} /$ liter which is equivalent to hydrogen-to-metal atom ratios 10-100.

Of course a complete nuclear power system must include the mass of the shield, power conversion subsystem, and the heat rejection unit. None of which are included in this paper. Nevertheless the data presented above represents the situation for an ideal solution reactor or a water lattice reactor. It indicates that the minimum mass is near $40-50 \mathrm{~kg}$. Any practical reactor will have to include reactor structural components and select fuel configurations and materials consistent the power conversion system that it is to be coupled to the reactor. The addition of other materials or voids will greatly increase the minimum practical mass that a reactor can be designed to. As a rule-of-thumb the critical mass of a system increases roughly proportionally to $1 /$ density $^{2}$ (Paxton 1986). Thus, assuming that all other design options remain constant, the dilution of fuel by a factor of $30-40 \%$ will nearly double the critical mass having a similar effect on the total system mass. These practical considerations are taken into account in the next section.

\section{CONFIGURATION OF UZRH PIN TYPE REACTORS}

The section above suggests that reactors having hydrogenous moderators are likely to have smaller masses those that do not. It further suggests that hydrogen-to-fissile metal atom ratio should be on the order of about 30/1. The use of $\mathrm{UZrH}$ as fuel allows for the inclusion of hydrogen in a reactor core while still permitting operating at relatively high fuel temperatures (up to $750 \mathrm{C}$ ). The SNAP-10a reactor, the only US reactor that has flown in space, used this fuel type (Johnson 1967 \& Anderson 1983). Because one of the purposes of this report is to identify reactor subsystems having minimum mass and to explore the possible mass reductions that one might achieve by replacing U-235 with U-233 or even Cm-245, we have restricted our investigations to $\mathrm{ZrH}$ dispersion fuels placed in stainless steel fuel pins. In this report reactor subsystem mass includes fuel pins, cladding, moderator, coolant, structure, radial and axial reflector, pressure vessel, and control mechanisms (10 kg).

\section{Enrichment and Weight Percent}

For $\mathrm{ZrH}_{\mathrm{x}}$ based dispersion fuels, the primary design variables are weight percent fissionable material, enrichment of fissionable material, fissionable isotope, and hydrogen stoichiometric ratio $x$. Other parameters such as pitch and fuel pin diameter are also important; however, their selection is strongly influenced by heat transfer and fluid dynamic limitations. The hydrogen stoichiometric ratio was selected at 1.65 because this $\mathrm{UZrH}$ is single phase over the temperature range of interest, and because the hydrogen vapor pressures are not too large at the maximum allowable fuel temperatures of $750 \mathrm{C}$. Table 1 lists the weight percents ranges investigated and the enrichments used for the various fuels.

TABLE 1. Weight percent and Enrichment of Fissionable Isotopes for $\mathrm{ZrH}_{165}$ Dispersion Fuel.

\begin{tabular}{lcc}
\hline Fissionable Isotope & Weight \% Fissionable Metal & Enrichment of Fissionable Isotope \\
\hline U-235/ U-238 & $10-45$ & 93.15 \\
U-233/U-234 & $10-45$ & 98.13 \\
Cm-245/ Cm-244 & $10-45$ & 10 \\
\hline
\end{tabular}

The upper range of Uranium or other heavy metal atom used in the $\mathrm{ZrH}$ fuel was set at $45 \mathrm{w} \%$. This value was selected because it is believed to be near the upper limit at which acceptable metallurgical and mechanical properties can be maintained. It is also the weight percent used in many of the Low Enrichment Uranium (LEU) replacement cores (UZR-27). The U-233 isotope is assumed to be enriched to 98.13 percent. This value was selected as it was used in Paxton (1986). The Curium isotopic composition was based on information provided by Benedict (1981). Table 2 lists the isotopic composition of $\mathrm{Cm}$ produced in a 1000 MWe PWR with self-generated Pu recycle. All nuclides but Cm-244 and Cm-245 have relatively short half-lives. If the $\mathrm{Cm}$ is obtained from existing sources of PWR fuel, then the isotopic ratio of $\mathrm{Cm}-245$ will be approximately $10 \%$. (Note that the calculations actually used $11.2 \%$ rather than $10 \%$. This difference probably makes little or no difference in the results.) 
TABLE 2. Isotopic composition of $\mathrm{Cm}$ produced in a 1000 Mwe PWR with self-generated Pu recycle (Benedict 1981) 60 days after discharge.

\begin{tabular}{lccc}
\hline Nuclide & $\mathrm{Kg} / \mathrm{Yr}$ & Half-life & Ratio of Nuclide to total \\
\hline $\mathrm{Cm}-242$ & 0714 & 163 days & 0.039 \\
$\mathrm{Cm}-243$ & 0.00861 & $32 \mathrm{yr}$ & $4.7 \mathrm{e}-4$ \\
$\mathrm{Cm}-244$ & 15.6 & $17.6 \mathrm{yr}$ & .857 \\
\hline $\mathrm{Cm}-245$ & 1.74 & $9300 \mathrm{yr}$ & 0.096 \\
\hline $\mathrm{Cm}-246$ & 0.174 & $5500 \mathrm{yr}$ & 0.0096 \\
\hline
\end{tabular}

\section{Neutron Transport Calculations and Reactor Geometry}

Reactor criticality neutron transport calculations were performed with the MCNP4b code (Briesmeister 1997), and the mass of the reactor was estimated by summing all the masses of the components. In all cases the reactor fuel consisted of a hexagonal array of fuel pins located in a core barrel (flow divider) surrounded by a bypass flow region. Three types of reactors were examined, water-cooled, gas-cooled and sodium-cooled. For each type of reactor the three fissile isotopes of fuel U-235, U-233 and Cm-245 were used. Figure 3 illustrates axial and longitudinal cuts of the reactor geometries used in the criticality calcuations. The water-cooled reactor used the bypass flow region as the radial reflector. Both the sodium and gas-cooled reactors used external $\mathrm{Be}$ radial and axial reflectors that were 35 and $25 \mathrm{~mm}$ respectively. In all cases the pressure vessel was assumed to be $9 \mathrm{~mm}$ thick.

The results of the calculations are presented Table 3 and summarized in Figure 4. Typically these calculations were performed by running MCNP4b with a given geometry, and then increasing or reducing the radius and height of the core to make the system critical with excess $k_{\text {eff }}$ of about $0.02-0.09$. Because the size and mass of the reflector, pressure vessel, and grid plate were keyed to the radius of the core, the total system mass would increase or decrease based primarily on the size of the core. Table 3 lists details
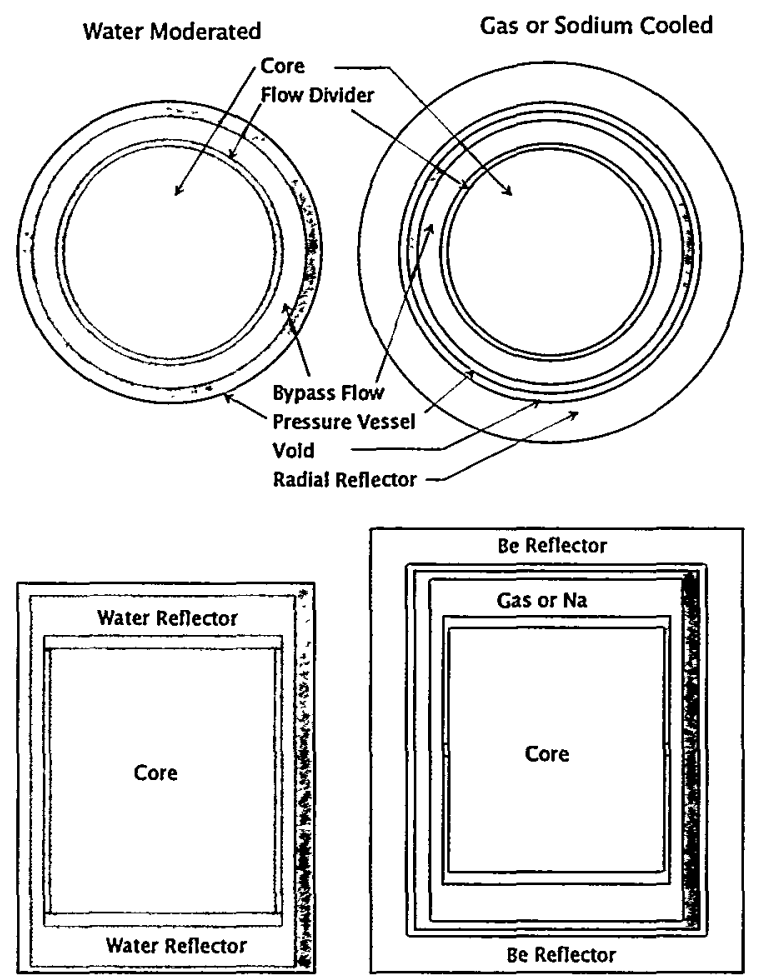

FIGURE 2. Axial and longitudinal cross sections of the MCNP4b transport geometry.

for the important variables used set up the geometry and to define the atom concentrations of various isotopes. Figure 4 summarizes the results of these calculations by plotting the total system mass as a function of hydrogen to metal ratio. The smallest mass system is a U-233 fueled water moderated reactor system. This system weighs $60 \mathrm{~kg}$ total and has $2.53 \mathrm{~kg}$ of U-233. Another very compact reactor is the U233 fuel gas cooled reactor. It has a total system mass of $109.2 \mathrm{~kg}$. A breakdown of the mass distribution 
for these two systems is listed in table 4. The major difference between these two systems is the mass of fuel and reflector required in the gas-cooled system. Also observe that the predicted reactor mass for a U235 fueled sodium cooled reactor was about $200 \mathrm{~kg}$, very close to the actual mass of SNAP-10A (220 kg, Johnson 1967).

\begin{tabular}{|l|l|l|l|l|l|l|l|l|}
\hline \multicolumn{2}{|l|}{ Table 4: Mass distribution in a U-233 water cooled and gas cooled reactor subsystem. } \\
\hline $\begin{array}{l}\text { Reactor } \\
\text { Subsystem }\end{array}$ & $\begin{array}{l}\text { Water/ } \\
\text { Gas }\end{array}$ & Clad & Fuel & Reflector & Pres. Ves. & Structure & Control & Total \\
\hline $\begin{array}{l}\text { U-233 Water } \\
\text { Uzrhw23_a.i }\end{array}$ & $5.1 \mathrm{~kg}$ & $2.0 \mathrm{~kg}$ & $5.8 \mathrm{~kg}$ & 8.1 & 25.2 & 4.1 & 10 & 60.3 \\
\hline $\begin{array}{l}\text { U-233 } \\
\text { Gas } \\
\text { Uzrhg23_b.i }\end{array}$ & 0.1 & 3.8 & 36.5 & 31.9 & 23.0 & 3.9 & 10 & 109.2 \\
\hline
\end{tabular}

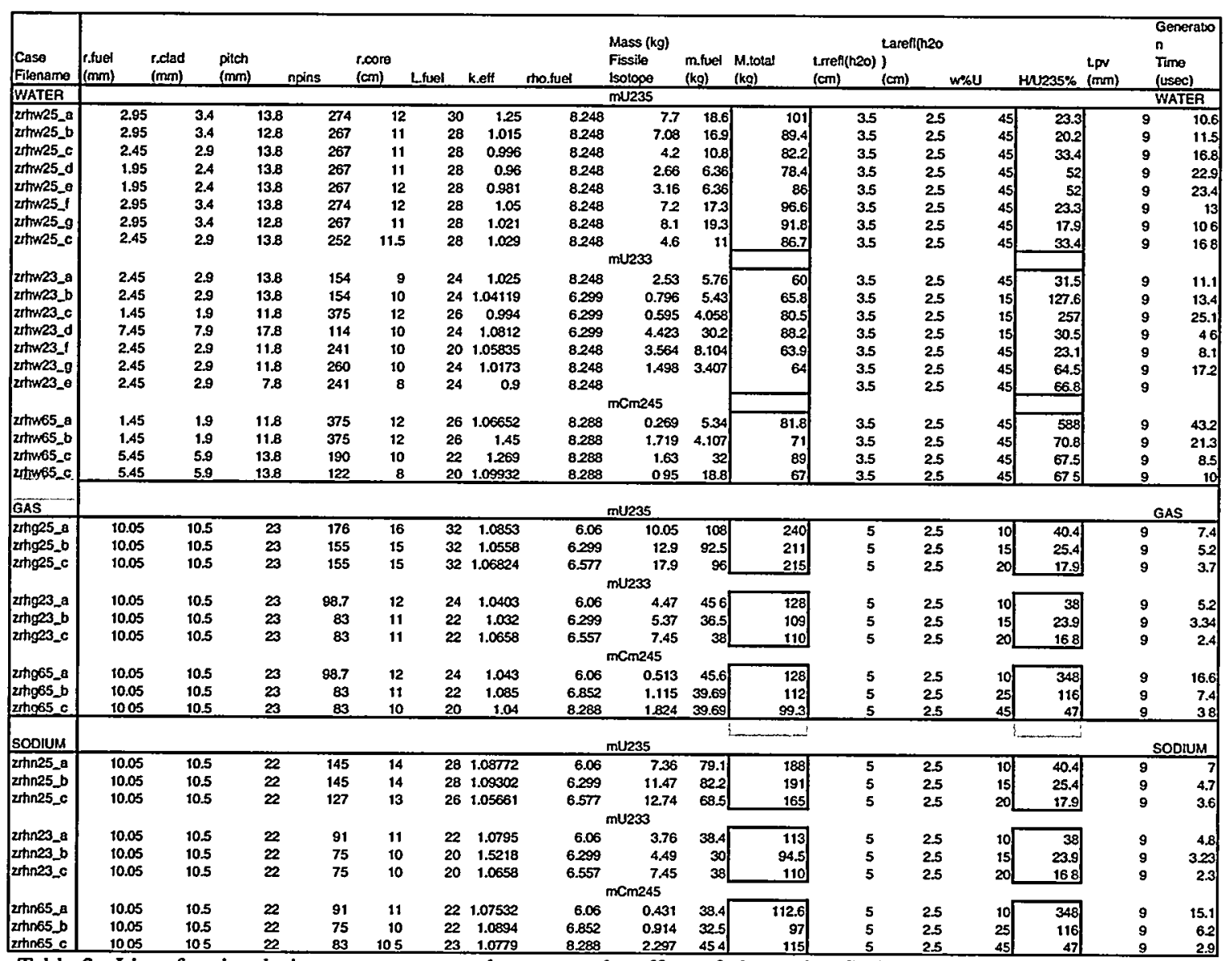

Table 3. List of major design parameters used to assess the effect of alternative fissile nuclides. Colored columns list the $\mathrm{H} / \mathrm{M}$ fissile atom ratio and the total reactor subsystem mass. Shield and power conversion are not included.

Based on examination of Table 3 and Figure 4, a number of observations can be made.

1. Water cooled/moderated systems have lower mass estimates than all other reactor subsystems studied.

2. The type of fissile isotope (U-233 or $\mathrm{Cm}-245)$ strongly influences reactor subsystem mass estimates in gas and sodium-cooled reactors. U-233 or Cm-245 fuel reduces the reactor subsystem by almost a factor of two from a similarly designed gas or sodium cooled U-235 system.

3. The type of fissile fuel type within water cooled/moderated does not strongly affect the mass of the reactor subsystem. 
4. For gas and sodium-cooled systems, higher $\mathrm{H} / \mathrm{M}$ ratios generally increase the system mass (about $1.3 \mathrm{~kg}$ per increment in $\mathrm{H} / \mathrm{M}$ ratio, e.g.; moving from an $\mathrm{H} / \mathrm{M}$ ratio of $15-20$ will increase the system mass by about $8 \mathrm{~kg}$.) . In water systems within the range of $H / M$ investigated there are no strong increases in system mass with increasing $\mathrm{H} / \mathrm{M}$ ratio. These observations are just a reflection of the observation made earlier in Figure 1. The total system mass has a broad minimum near H/M ratios near 30.

5. Sodium cooled systems have lower mass estimates than do gas systems. This is occurred in these calculations because we assumed that the pitch could be reduced compared to a gas-cooled system because sodium is such a good coolant which allowed increasing the average density fissile isotope within the core.

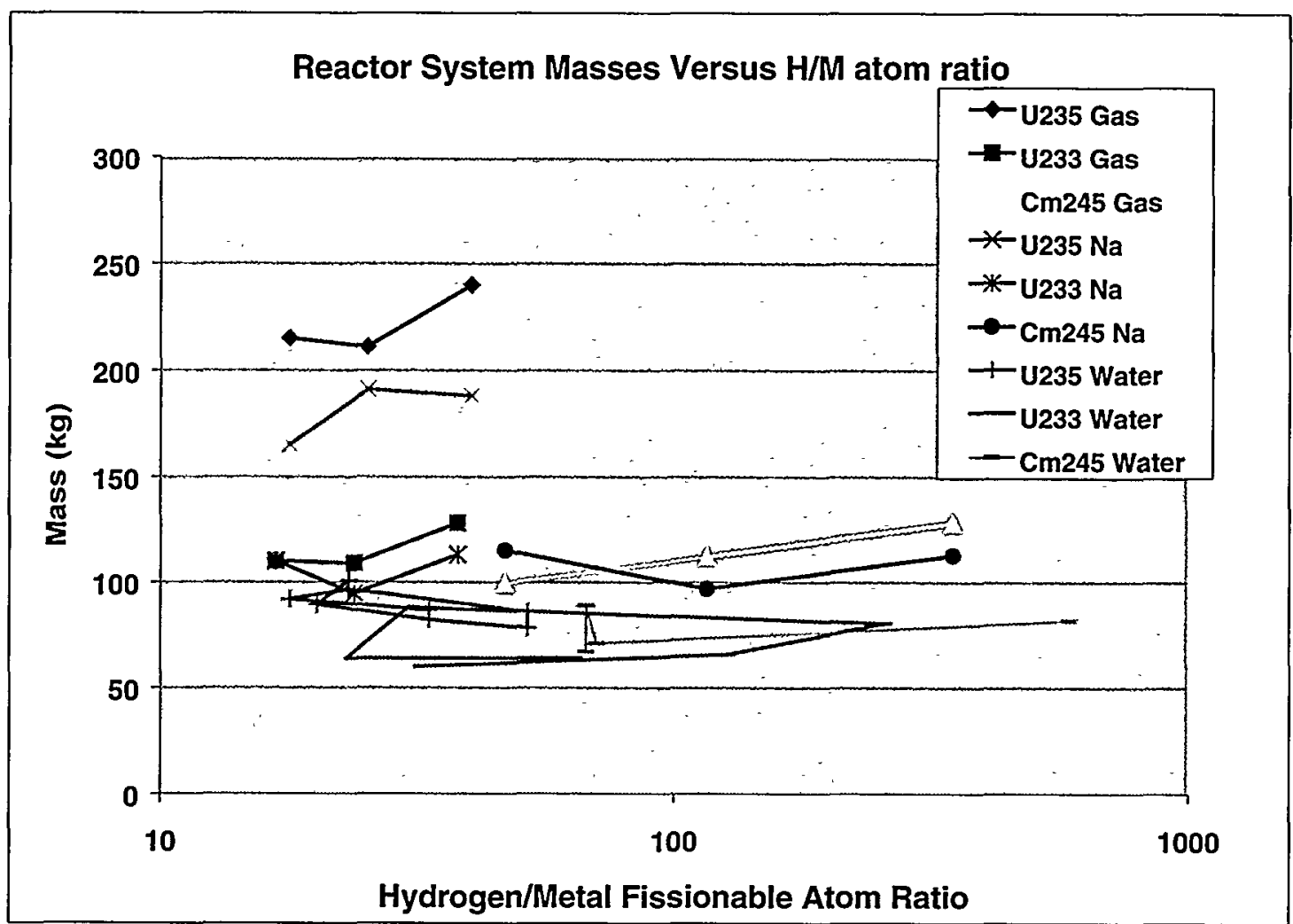

Figure 3. Graph of total reactor subsystem mass as a function of $\mathrm{H} / \mathrm{M}$ fissile atom ratio.

\section{CONCLUSIONS}

This report attempts to determine how small can nuclear reactor subsystems can be designed to and still be capable of operating at $60 \mathrm{~kW}$ thermal. It investigates the effect of Hydrogen to fissile metal atom ratio, water versus gas or sodium cooling, and alternative fissile isotopes. The result of this analysis indicate that very low mass systems can be identified and they have total reactor subsystem masses on the order of 60 for water cooled U-233 systems and $110 \mathrm{~kg}$ for gas or sodium cooled U-233 reactors. Low enrichment of Cm-245 available from spent fuel appears to offer no real advantage over U-233 reactor cores.

Water cooled UZrH fuel reactors that use steam Rankine power conversion systems should seriously be considered for use in space and planetary reactor applications because of the very low mass reactors that can be developed. Other advantages are that they operate at low temperature $(\sim 250 \mathrm{C})$, have high power conversion efficiencies, and have long life. Furthermore the fuel type is fully developed, commercially available, has been used in over 60 TRIGA research reactors, is well characterizied, has unique safety features including prompt negative temperature coefficient of reactivity, and has high fission product retention. All of these features will tend to lower the cost and risk associated with developing a successful 
space reactor. Still the use of water in weightless space or very cold planet surfaces (especially for power conversion) must be fully developed and tested.

R. V. Anderson, et. al., "Space-Reator Electirc Systems: Subsystem Technology Assessment", Rockwell International, ESG-DOE13398, DE83 01308, March 1983.

M. Benedict, T. H. Pigford , H. W. Levi, "Nuclear Chemical Enegineering", 1987, page 370.

R. A. Johnson, W. T. Morgan, and S. R Design, Ground Test, and Flight Test of SNAP 10A, First Reactor in Space", Nuclear Engineering and Design, Vol. 5, pp7-20, 1967.

R. A. Knief, "Nuclear Criticality Safety Theory and Practice", 1998.

Paxton H.C. and Pruvost N. L, "Critical Dimension os Systems Containing 235U, 239Pu, and 233U, 1986 Revision LA-10860-MS

(July 1967).

Briesmeister Judith F. "MCNP - A General Monte Carlo N-Particle Transport Code Version 4B", UC705 and UC700, LA-12625-M, Version 4B Manual, March 1997.

Sandia is a multiprogram laboratory operated by Sandia Corporation, a Lockheed Martin Company, for the United States Deparment of Energy under contract DE-AC04-94AL85000. 